\title{
Rapid Synthesis of Bismuth Molybdate Nanoplates for Supercapacitor Applications by Microwave Combustion Method
}

\author{
A. Shameem, V. Siva, A. Murugan, Shamima Hussain, S. Asath Bahadur*
}

\begin{abstract}
Orthorhombic structured bismuth molybdate $\left(\mathrm{Bi}_{2} \mathrm{MoO}_{6}\right)$ is obtained by one pot microwave combustion method. The characteristic performance of $\mathrm{Bi}_{2} \mathrm{MoO}_{6}$ nanocatalyst are described by X-ray diffraction (XRD), Scanning Electron Microscopy (SEM) furnished with Energy - dispersive X-ray spectroscopy (EDS) and Fourier change infrared (FT-IR) spectroscopy. The average crystallite size for $\mathrm{Bi}_{2} \mathrm{MoO}_{6}$ estimated from XRD is about $28.9 \mathrm{~nm}$. The surface morphology from SEM pictures displays nanoplates. The FTIR is utilized to recognize the structural coordination and the presence of functional group. The electrochemical studies are taken to readily comprehend the electrochemical performance of the modified active electrode with notable specific capacitance value are found $234.9 \mathrm{Fg}^{-1}$ at $5 \mathrm{mVs}^{-1}$ and cyclic retention is stable up to 900 cycles (98.7\%). The as-synthesized dynamic material acts as a novel electrode material for supercapacitor.
\end{abstract}

Keywords: $\mathrm{Bi}_{2} \mathrm{MoO}_{6}$, Microwave combustion method, Nanoplates, Electrochemical performance.

\section{INTRODUCTION}

S upercapacitors having larger power densities as well as superior cycle stability have drawn significant consideration in course of recent years because of the increased energy anxiety and natural pollutant issues [1]-[4]. Recently, various nanomaterials with large specific surface areas are examined through enhanced charge gathering and ion transportation for electrochemical usage [4]-[8]. Also, the manufacture of fascinating nano-architectures is additionally considered as a powerful technique to uplift the electrochemical behaviours.

Revised Manuscript Received on December 15, 2019.

A. Shameem, Department of Physics, School of Advanced Sciences \& Condensed Matter Physics Laboratory, International Research Centre, Kalasalingam Academy of Research and Education, Krishnankoil, Tamil Nadu, India - 626126. Email: shameemirfu@ gmail.com

V. Siva, Department of Physics, School of Advanced Sciences \& Condensed Matter Physics Laboratory, International Research Centre, Kalasalingam Academy of Research and Education, Krishnankoil, Tamil Nadu, India - 626126. Email: vsiva33.physics@ gmail.com

A. Murugan, Department of Physics, School of Advanced Sciences\& Condensed Matter Physics Laboratory, International Research Centre, Kalasalingam Academy of Research and Education, Krishnankoil, Tamil Nadu, India - 626126. Email: murugan027@gmail.com

Shamima Hussain, UGC-DAE CSR Kalpakkam Node, Kokilamedu, Kalpakkam, Tamil Nadu, India- 603104. Email: sh@csr.res.in

S. Asath Bahadur*, Department of Physics, School of Advanced Sciences \& Condensed Matter Physics Laboratory, International Research Centre, Kalasalingam Academy of Research and Education, Krishnankoil, Tamil Nadu, India - 626126. Email: s_a bahadur@yahoo.co.in
As of late, the discerning structure of nanosheets [6], [9], [10] nanowire [3], [11] and nanorod [4], [12] has been considered as an incredible accomplishment in electrochemical (EC) research.

Bismuth molybdate $\left(\mathrm{Bi}_{2} \mathrm{MoO}_{6}\right)$, an Aurivillius (orthorhombic) type structure is broadly utilized in photocatalytic applications because of their interesting optical and electric behaviours [13]. Also, they are contemplated as an excellent electrode material for supercapacitors. Moreover, it is utilized as an admirable electrode material in supercapacitors, conveys a high specific capacitance with great cyclic stability. This may be because of the fractional dissolution of $\left(\mathrm{Bi}_{2} \mathrm{O}_{2}\right)_{\mathrm{n}}{ }^{2+}$ ionic species with incremental active sites. Yet its EC execution is much lower because of their adverse electron transfer. As revealed, $\mathrm{Bi}_{2} \mathrm{MoO}_{6}$ nanosheets acquiesce a capacitance of $25 \mathrm{~F} \mathrm{~g}^{-1}$ at $5 \mathrm{mVs}^{-1}$ in $1 \mathrm{M} \mathrm{NaCl}$ electrolyte [10]. However, their EC properties should be improved practically for applications. As a result, many researchers focused their attention and interest for the development of high performed electrochemical device.

The combustion method facilitated with microwave irradiation, which conspicuously decreases the reaction time, having improved command over dimension and structure of the nanomaterials. This preparation strategy is exceptional as it has numerous favourable circumstances like upgraded response energy, specific materials coupling, quick volumetric warming, high response rate, expanded item yield, most virtue item, and so forth than traditional strategies. Moreover, this technique can suppress the by-products during preparation [2], [4], [5], [14]. They are significant for nanostructured materials development which relies upon the response condition. Only few reports are available on the development of $\mathrm{Bi}_{2} \mathrm{MoO}_{6}$ nanoplates exhibits for electrochemical applications. Herein the present work, we report a $\mathrm{Bi}_{2} \mathrm{MoO}_{6}$ nanoplates array on $\mathrm{Ni}$ foil, which was effectively achieved by one pot microwave combustion method. The outcomes demonstrate to facilitate the $\mathrm{Ni}$ foil-based materials display a prevalent EC behaviour with a high specific capacitance. The nanoplate cluster structures could provide huge surface area and excellent electron transport execution for high rate supercapacitors. 


\section{EXPERIMENTAL}

\section{A. Material and methods}

Bismuth nitrate pentahydrate, Sodium molybdate dehydrate and Urea were bought from Merck, India with AR grade materials. Double distilled (DD) water was utilized all through this investigations. Ethanol was acquired from Sigma Aldrich.

$\mathrm{Bi}_{2} \mathrm{MoO}_{6}$ nanoplates has been prepared by a simple microwave combustion method as depicted earlier [2], [4], [5]. $\mathrm{Bi}\left(\mathrm{NO}_{3}\right)_{3} \cdot 5 \mathrm{H}_{2} \mathrm{O}, \mathrm{Na}_{2} \mathrm{MoO}_{4} \cdot 2 \mathrm{H}_{2} \mathrm{O}$ and $\mathrm{CO}\left(\mathrm{NH}_{2}\right)_{2}(1: 1: 4$ molar ratio) were each dissolved together in $50 \mathrm{~mL}$ of DD water under magnetically stirred in ambient condition. Then the solution was moved into a domestic microwave oven IFB-20PG3S. After the reaction, the precipitates were confined and wash down with DD water and ethanol, and dried at oven a night.

\section{B. Characterization and working electrode preparation}

The crystal structure of $\mathrm{Bi}_{2} \mathrm{MoO}_{6}$ was confirmed by Bruker D8 advance ECO XRD systems possesses SSD160 1D Detector XRD. The morphology and elemental confirmation can be investigated utilizing scanning electron microscope: ZEISS EVO 18 Research attached with EDS . The Fourier transform infrared spectra of the powders have been occupied with the scope of $4000-400 \mathrm{~cm}^{-1}$ by Shimadzu (IR Tracer-100) spectrophotometer by KBr pellet procedure. The household IFB-20PG3S microwave have been utilized for the preparation having $1000 \mathrm{~W}$ with vitality $2.45 \mathrm{GHz}$.

Moreover, the electrochemical measurements of electrodes made utilizing as-prepared $\mathrm{Bi}_{2} \mathrm{MoO}_{6}$ were measured with help of cyclic voltammetry (CV), galvanostatic charge-discharge (GCD) and electrochemical impedance spectroscopy (EIS) systems by the assistance of electrochemical workstation (Model-CHI 6008E, USA). EC execution of an active altered electrode is performed within 3 $\mathrm{M} \mathrm{KOH}$ electrolyte. The three-electrode cell setup made up of altered $\mathrm{Bi}_{2} \mathrm{MoO}_{6}$ as a working terminal, $\mathrm{Pt}$ electrode as a counter terminal and $\mathrm{Ag} / \mathrm{AgCl}$ electrode as a reference terminal. The combination of $\mathrm{Bi}_{2} \mathrm{MoO}_{6}$ : acetylene black $(85: 15)$ with suitable amount of Nafion (binder) was utilized to form slurry and after that spread on Nickel foil $\left(1 \times 1 \mathrm{~cm}^{2}\right)$.

\section{RESULT AND DISCUSSION}

\section{A. XRD analysis}

Figure1 illustrates a XRD pattern of $\mathrm{Bi}_{2} \mathrm{MoO}_{6}$ at diffraction peaks between $2 \theta=10-80^{\circ}$. The diffraction peaks have been recorded to be orthorhombic system with koechlinite phase, relating to JCPDS Card no.: 76-2388. The sample has a high level of crystallinity which is clarified by sharp and strong peaks. It is exposed that all the diffraction peaks are promptly recorded to end-centred lattice bismuth molybdenum oxide, with lattice constants: $a=5.50 \AA, b=16.24 \AA$, and $c=5.49 \AA$. The prepared $\mathrm{Bi}_{2} \mathrm{MoO}_{6}$ are orthorhombic crystal structure and Cmca(64) space group. The average crystallite size of $\mathrm{Bi}_{2} \mathrm{MoO}_{6}$ was determined by well-known Scherrer equation,

$$
\boldsymbol{D}=\frac{k \lambda}{\beta \operatorname{Cos} \theta} \mathrm{nm}
$$

The average crystallite size was observed around $28.9 \mathrm{~nm}$.

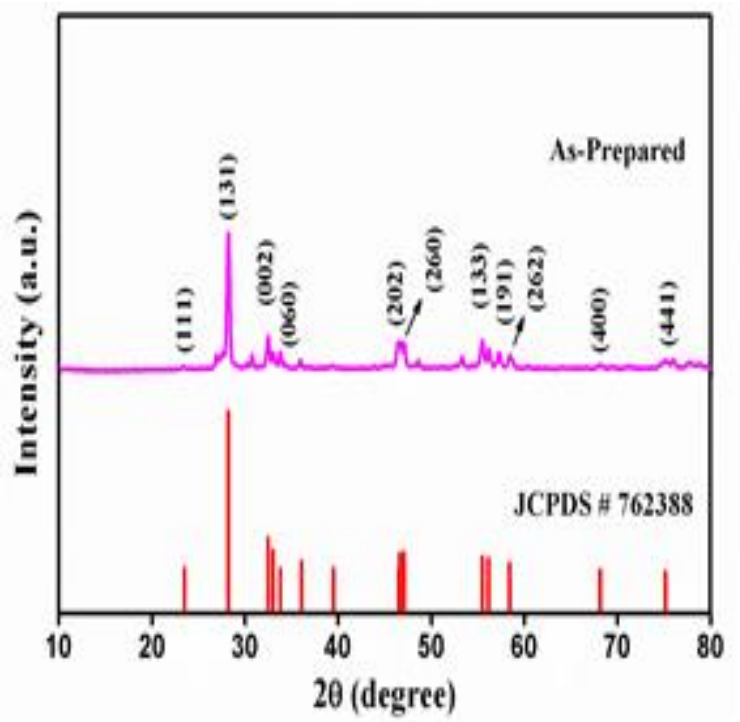

Fig. 1. Powder XRD plots of $\mathrm{Bi}_{2} \mathrm{MoO}_{6}$ nanoparticles with JCPDS number

\section{B. FT-IR}

Figure 2 represents the FT-IR spectrum of the $\mathrm{Bi}_{2} \mathrm{MoO}_{6}$. A small band is credited at $2320 \mathrm{~cm}^{-1}$ might be a result of $\mathrm{CO}_{2}$ or nitrile group. The significant peaks at $400-910 \mathrm{~cm}^{-1}$ have been generally associated to $\mathrm{Bi}-\mathrm{O}, \mathrm{Mo}-\mathrm{O}$ extending and Mo-O-Mo connected stretching modes [15]. A peaks around $845 \mathrm{~cm}^{-1}$ distributed as asymmetric and a blind peak at 797 $\mathrm{cm}^{-1}$ as symmetric stretching modes of $\mathrm{Mo}-\mathrm{O}_{6}$ identifying with the vibrations of $O$ atoms. A peak at $720 \mathrm{~cm}^{-1}$ is credited as an asymmetric stretching of $\mathrm{Mo}^{-} \mathrm{O}_{6}$ including vibrations of the central $\mathrm{O}$ atom. A peak near $567 \mathrm{~cm}^{-1}$ convey as a bending vibration of Mo- $\mathrm{O}_{6}$. Besides, a peak attributed at $456 \mathrm{~cm}^{-1}$, which is allocated for stretching and bending vibrations of $\mathrm{Bi}-\mathrm{O}_{6}$, asserting the structure of the crystal [16].

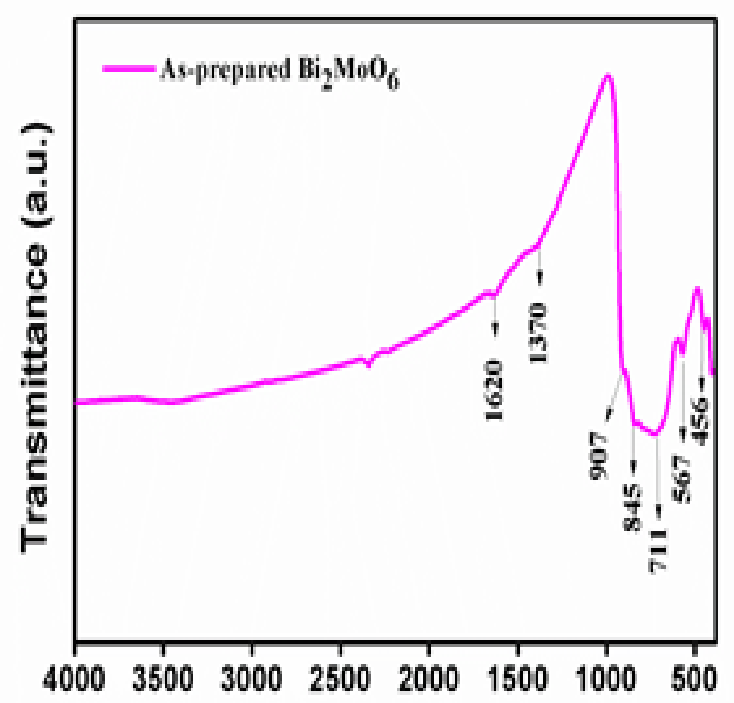

\section{Wavenumber $\left(\mathrm{cm}^{-1}\right)$}

Fig. 2. FT-IR spectrum of $\mathrm{Bi}_{2} \mathrm{MoO}_{6}$ nanoplates. 


\section{SEM with EDS}
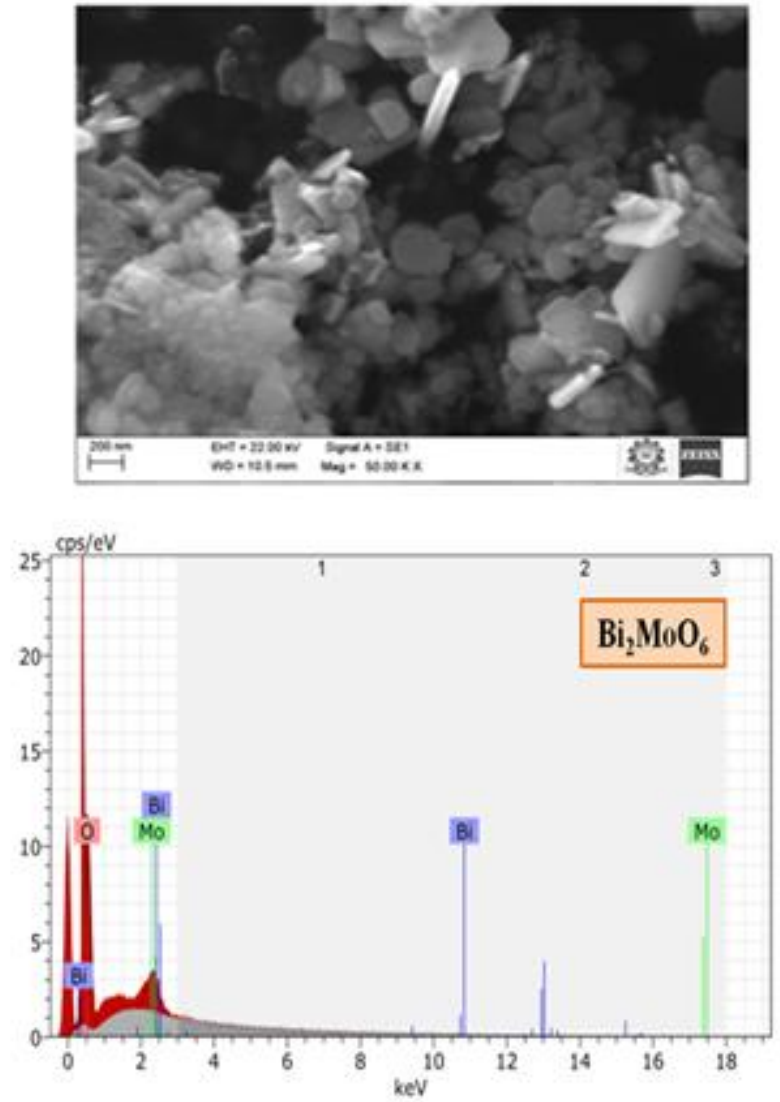

Fig. 3. (a) SEM picture and (b) EDS spectrum of $\mathrm{Bi}_{2} \mathrm{MoO}_{6}$ nanoplates

The preliminary seed crystallographic stage is a fundamental factor responsible for the shape affirmation of the crystals. At the point when the crystalline stage is settled, the ascribed cell structures of the seeds solidly impact further development [17]. The $\mathrm{Bi}_{2} \mathrm{MoO}_{6}$ involves turning $\left(\mathrm{Bi}_{2} \mathrm{O}_{2}\right)_{\mathrm{n}}{ }^{2+}$ stratum, perovskite-like $\left(\mathrm{MoO}_{4}\right)_{\mathrm{n}}{ }^{2-}$ stratum, and octahedral Mo chains assure in the intense intrinsic anisotropic improvement in various molybdates [18]. The surface morphology of $\mathrm{Bi}_{2} \mathrm{MoO}_{6}$ was confirmed using SEM and ascribed in figure 3 (a) which affirms that the as-prepared nanomaterials having the uniform size nanoplates like structures.

A fine homogeneity was seen for $\mathrm{Bi}_{2} \mathrm{MoO}_{6}$ by $\mathrm{EDS}$ relating with XRD pattern. It is worth seen that the occurrence of $\mathrm{Bi}$, $\mathrm{Mo}, \mathrm{C}$ and $\mathrm{O}$ by EDS analysis and is shown in figure 3(b). The $\mathrm{C}$ presence is because of the carbon tape utilized in EDS analysis. The component offers further bits of knowledge for the basic preparation and dispersion inside the $\mathrm{Bi}-\mathrm{Mo}-\mathrm{O}$ nanomaterials. $\mathrm{Bi}, \mathrm{Mo}$, and $\mathrm{O}$ in $\mathrm{Bi}_{2} \mathrm{MoO}_{6}$ are very much disseminated, representing that they can be portrayed as Bi-Mo-O combinations.

\section{Electrochemical Properties}

\section{a. Cyclic Voltammetry analysis}

Figure 4 (a) shows $\mathrm{CV}$ curves of modified $\mathrm{Bi}_{2} \mathrm{MoO}_{6}$ electrodes attained on different scan rates $\left(5-75 \mathrm{mVs}^{-1}\right)$ in the potential scope of -1.0 to $0 \mathrm{~V}$. From the $\mathrm{CV}$ analysis, it represents pseudocapacitive behavior. The capacitance characteristics that the electrode is managed by Faradaic, crediting a reversible redox reaction. To procure information about the capacitive properties, specific capacitance $\left(\mathrm{C}_{\mathrm{sp}}\right)$ estimations of the bismuth molybdate nanoplates are determined utilizing

$$
\mathrm{C}_{\mathrm{sp}}=\int \mathrm{Idv} / \mathrm{sm} \Delta \mathrm{V}
$$

Where, $\int \mathrm{Idv}$ - area of the CV curve (A), s-scan rate $\left(\mathrm{Vs}^{-1}\right)$, $\Delta \mathrm{V}$-potential window $(\mathrm{V})$ and $\mathrm{m}$-mass of the material $(\mathrm{g})$. The $\mathrm{C}_{\mathrm{sp}}$ values are intended for various scan rates and were plotted in figure 4 (b). The CV curve display two oxidation peaks because of the event, reversible faradaic practice of bismuth $\left(\mathrm{Bi}^{3+}\right.$ to $\left.\mathrm{Bi}^{0}\right)$ by electrolytic ion diffusion process [19]. The calculated $\mathrm{C}_{\mathrm{sp}}$ values are 234.9, 227.14, 200.2, 190.96 and $144.06 \mathrm{Fg}^{-1}$ at different scan rate from 5 to $75 \mathrm{mVs}^{-1}$ respectively. In addition, a positive shift of oxidation peaks and negative shift of reduction peaks are noticed, signifying the reversible faradaic redox response of active electrode is improved with increase in scan rate [19].
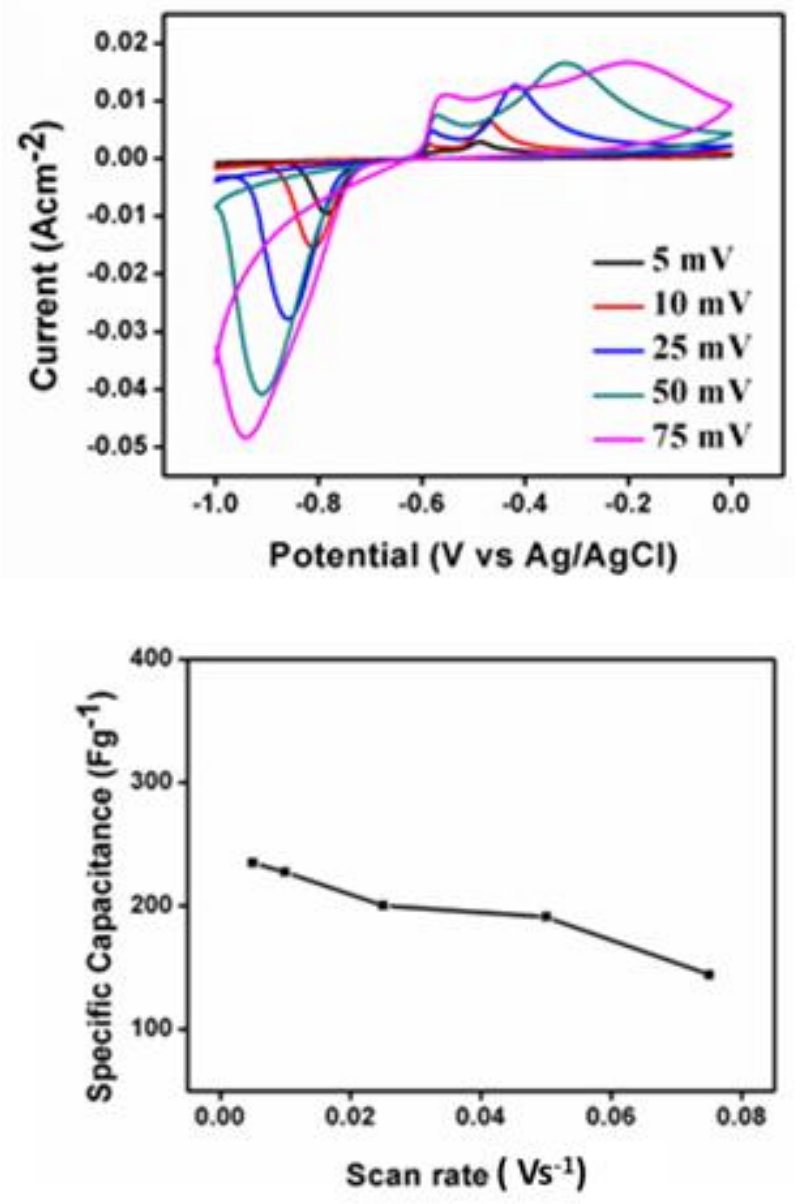

Fig. 4. (a) $\mathrm{CV}$ curves of $\mathrm{Bi}_{2} \mathrm{MoO}_{6}$ nanomaterials The $\mathrm{CV}$ measurements of prepared sample at a scanning rate of 5

- $75 \mathrm{mV} \mathrm{s}^{-1}$ in $3 \mathrm{M} \mathrm{KOH}$ electrolyte and (b) $\mathrm{C}_{\mathrm{sp}}$ of the samples versus scan rate.

\section{b. Chronopotentiometry}

Figure 5 (a) signifies the GCD estimation connected with various current densities ( 1 to $7 \mathrm{~mA} \mathrm{~cm}^{-2}$ ) contained by potential -1 to $0 \mathrm{~V}$. At all current densities perception indicates symmetric potential versus time curves.

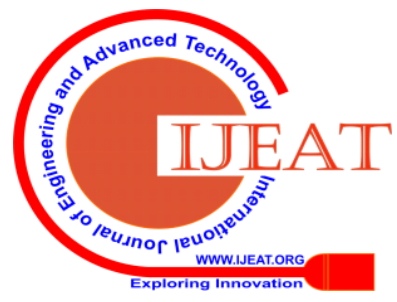


It recommends prevalent charge-discharge columbic competence with lesser polarization of active materials in the pseudocapacitive profile [20]. The $\mathrm{C}_{\mathrm{sp}}$ value is much higher than previous report [21]. The cyclic execution is another critical authenticity for supercapacitors in suitable exercise. The elongated cyclic execution of the electrode was evaluated through a constant GCD release system to 1500 cycles at a current density of $3 \mathrm{~A} \mathrm{~g}^{-1}$ is represented in figure 5 (b). The capacitance retention almost remains constant up to 900 cycles $(98.7 \%)$ and behaves little drop to $92.3 \%$ after 1500 cycles. It might be because of the better contact between the sample and electrolyte. Impressing, the cyclic stability remains stable than the previously reported [21]. These results keep the insight for high performed supercapacitors.

Fig. 5. (a) GCD curves at various current densities and (b) Cycling performance of the $\mathrm{Bi}_{2} \mathrm{MoO}_{6}$ nanoplates at $3 \mathrm{~A} \mathrm{~g}^{-1}$.

\section{c. Electrochemical impedance spectroscopy}

So as to expose the cause for the electrochemical properties of electrodes, EIS are described as well Nyquist plots are exposed in figure 6. The curve exhibits two segments: two semicircles within a low-frequency region and a high-frequency region. Semicircle occurrence in low frequency may be the result of diffusion and accumulation of ions in electrode-electrolyte interface region. The sample
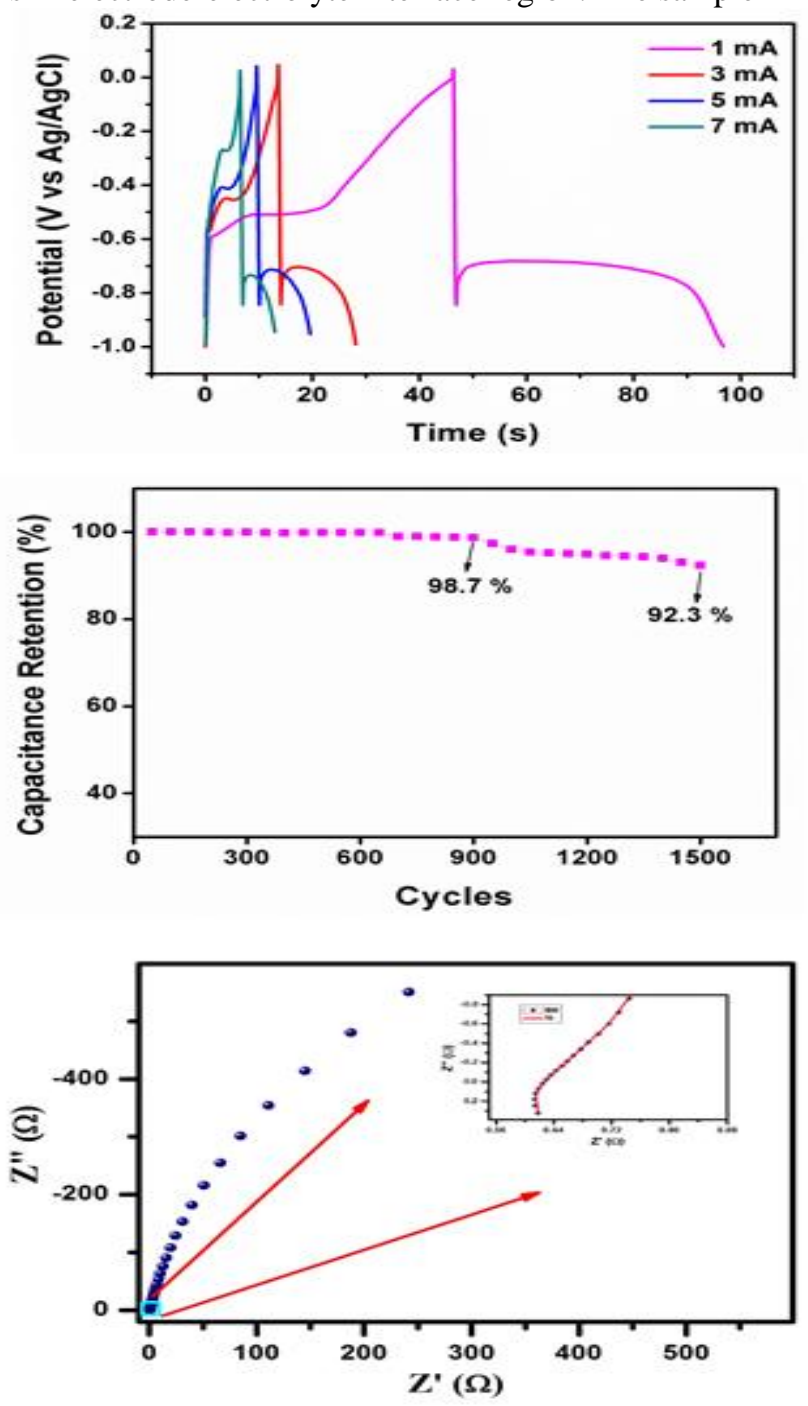

Fig. 6 EIS Nyquist plots of active $\mathrm{Bi}_{2} \mathrm{MoO}_{6}$. resistance $\left(\mathrm{R}_{\mathrm{s}}\right)$ due to its static charge carrier is measured to be $0.60 \Omega$ at lower frequency. Charge-transfer resistance $\left(R_{c t}\right)$ is measured within the region of semicircle in the frequency region and found to be $0.05 \Omega$. [22], [23].

\section{CONCLUSION}

The nanostructured $\mathrm{Bi}_{2} \mathrm{MoO}_{6}$ nanoplates were effectively prepared by one pot microwave assisted combustion method. XRD pattern exposed orthorhombic koechlinite $\mathrm{Bi}_{2} \mathrm{MoO}_{6}$ system with an average crystallite size of $28.9 \mathrm{~nm}$. SEM pictures were delineates nanoplates morphology and the presence of appropriate components was in EDS. FT-IR spectrum were utilized for the recognition of structural coordination. XRD, EDS and FT-IR authenticate the prepared $\mathrm{Bi}_{2} \mathrm{MoO}_{6}$ is impurity free sample. The electrochemical performance was studied and approves the faradaic pseudocapacitive profile. An upgraded $\mathrm{C}_{\mathrm{sp}}$ sophisticated with $92.3 \%$ retentivity after 1500 cycles. The engineered system bears a fruitful technique to make improved nanostructures for the utilization in supercapacitors.

\section{ACKNOWLEDGMENT}

Authors A. S, P. D, S. H and S. A. B would like to acknowledge UGC-DAE-CSR, Kalpakkam Node, Tamil Nadu, India for grants support through a project (Ref. No. CSR-KN/CSR-103/2018-19/1042).

\section{REFERENCES}

1. X. H. Xia, C. G. Zhu, J. S. Luo, "Synthesis of free-standing metal sulfide nanoarrays via anion exchange reaction and their electrochemical energy storage application," Small, vol. 10, 2014, pp 766-773.

2. A. Shameem, P. Devendran, V. Siva, R. Packiaraj, N. Nallamuthu, S. Asath Bahadur, "Electrochemical performance and optimization of $\alpha$-NiMoO4 by different facile synthetic approach for supercapacitor application," J. Mater. Sci.:Mater. Electron., vol. 30 (4), 2019, pp 3305-3315.

3. C. Zhou, Y. W. Zhang, Y. Y. Li, J. P. Liu, "Construction of high-capacitance 3D CoO@polypyrrole nanowire array electrode for aqueous asymmetric supercapacitor," Nano Lett., vol. 13, 2013, pp 2078-2085

4. A. Shameem, P. Devendran, V. Siva, K. S. Venkatesh, A. Manikandan, S. Asath Bahadur, N. Nallamuthu, "Dielectric Investigation of NaLiS Nanoparticles Loaded on Alginate Polymer Matrix Synthesized by Single Pot Microwave Irradiation," J. Inorg. Organomet. Polym. Mater., vol. 28 (3), (2018), pp 671 - 678.

5. K. Seevakan, A. Manikandan, P. Devendran, A. Shameem, T. Alagesan, "Microwave combustion synthesis, magneto-optical and electrochemical properties of $\mathrm{NiMoO}_{4}$ nanoparticles for supercapacitor application," Ceram. Int., vol. 44 (12), 2018, pp 13879-13887.

6. X. H. Xia, J. P. Tu, Y. Q. Zhang, J. Chen, X. L. Wang, C. D. Gu, C. Guan, J. S. Luo, H. J. Fan, "Porous hydroxide nanosheets on performed nanowires by electrodeposition: branched nanoarrays for electrochemical energy storage," Chem. Mater., vol. 24, 2012, pp 3793-3799.

7. V. D. Nithya, R. K. Selvan, L. Vasylechko, "Effect of carbon coating on the electrochemical properties of $\mathrm{Bi}_{2} \mathrm{WO}_{6}$ nanoparticles by PVP-assisted sonochemical method," J. Appl. Electrochem., vol. 45, 2015, pp 473-485.

8. Y. J. Li, N. Yu, P. Yan, "Fabrication of manganese dioxide nanoplates anchoring on biomass-derived cross-linked carbon nanosheets for high-performance asymmetric supercapacitors," J. Power Sources, vol 300, 2015, pp 309-317. 
9. C. Z. Yuan, L. Yang, L. R. Hou, L. F. Shen, X. Q. Zhang, X. W. Lou, "Growth of ultrathin mesoporous $\mathrm{Co}_{3} \mathrm{O}_{4}$ nanosheet arrays on $\mathrm{Ni}$ for high-performance electrochemical capacitors," Energy Environ. Sci., vol. 5, 2012, pp 7883-7887.

10. B. Senthilkumar, R. K. Selvan, L. Vasylechko, M. Minakshi, "Synthesis, crystal structure and pseudocapacitor electrode properties of gamma-Bi ${ }_{2} \mathrm{MoO}_{6}$ nanoplates," Solid State Sci., vol. 35, 2014, pp 18-27.

11. Q. Q. Hu, W. Q. Ma, G. Liang, H. H. Nan, X. T. Zheng, X. J. Zhang, "Anion-exchange reaction synthesized $\mathrm{CoNi}_{2} \mathrm{~S}_{4}$ nanowires for superior electrochemical performances," RSC $A d v$., vol. 5, 2015, pp 84974-84979.

12. X. H. Lu, D. Z. Zheng, T. Zhai, Z. Q. Liu, Y. Y. Huang, S. L. Xie, Y. X Tong, "Facile synthesis of large-area manganese oxide nanorod arrays as a high-performance electrochemical supercapacitor," Energy Environ. Sci., vol. 4, 2011, pp 2915-2921.

13. J. L. Long, S. C. Wang, H. J. Chang, B. Z. Zhao, B. T. Liu, Y. G. Zhou, W. Wei, X. X. Wang, L. Huang, W. Huang, " $\mathrm{Bi}_{2} \mathrm{MoO}_{6}$ Nanobelts for Crystal Facet-Enhanced Photocatalysis," Small, vol. 10, 2014, pp 2791-2795.

14. J.H. Ryu, S.M. Koo, J.W. Yoon, C.S. Lim, K.B. Shim, "Synthesis of nanocrystalline $\mathrm{MMoO}_{4}(\mathrm{M}=\mathrm{Ni}, \mathrm{Zn})$ phosphors via a citrate complex route assisted by microwave irradiation and their photoluminescence," Mater. Lett., vol. 60, 2006, pp 1702-1705

15. M. Maczka, W. Paraguassu, A.G. Souza Filho, P.T.C. Freire, J. Mendes Filho, J.Hanuza, "Phonon-instability-driven phase transitions in ferroelectric $\mathrm{Bi}_{2} \mathrm{WO}_{6}: \mathrm{Eu}^{3+}$ : High-pressure Raman and photoluminescence studies", Phys. Rev. B, vol. 77, 2008, pp 094137 $1-9$

16. L. Zhang, T. Xu, X. Zhao, Y. Zhu, "Controllable synthesis of Bi2MoO6 and effect of morphology and variation in local structure on photocatalytic activities," Appl. Catal., B: Environ., vol. 98, 2010, pp 138-146.

17. Y.W. Jun, J.S. Choi, J. Cheon, "Shape Control of Semiconductor and Metal Oxide Nanocrystals through Nonhydrolytic Colloidal Routes,' Angew. Chem. Int. Ed., vol. 45, 2006, pp 3414-3439.

18. N. Kim, R.N. Vannier, C.P. Grey, "Detecting Different Oxygen-Ion Jump Pathways in $\mathrm{Bi}_{2} \mathrm{WO}_{6}$ with 1- and 2-Dimensional $17 \mathrm{O}$ MAS NMR Spectroscopy," Chem. Mater., vol. 17, 2005, pp 1952-1958.

19. B. Sarma, A.L. Jurovitzki, Y.R. Smith, S.K. Mohanty, M. Misra "Redox-induced enhancement in interfacial capacitance of the titania nanotube/bismuth oxide composite electrode," ACS Appl. Mater. Inter., vol. 15, 2013, pp1688-1697.

20. C. Yuan, J. Li, L. Hou, X. Zhang, L. Shen, X. Wen Lou, "Ultrathin Mesoporous $\mathrm{NiCo}_{2} \mathrm{O}_{4}$ Nanosheets Supported on Ni Foam as Advanced Electrodes for Supercapacitors," Adv. Funct. Mater., vol. 22, 2012, pp 4592.

21. T. Yu, Z. Li, S. Chen, Y. Ding, W. Chen, X. Liu, Y. Huang, F. Kong, "Facile synthesis of flower-like $\mathrm{Bi}_{2} \mathrm{MoO}_{6}$ hollow microspheres for high-performance supercapacitors," ACS Sustainable Chem. Eng. (2018) (DOI: 10.1021/acssuschemeng.7b04673).

22. S. D. Min, C. J. Zhao, G. R. Chen and X. Z. Qian, "One-pot hydrothermal synthesis of reduced graphene oxide/ $\mathrm{Ni}(\mathrm{OH})(2)$ films on nickel foam for high performance supercapacitors," Electrochim. Acta, vol. 115, 2014, pp 155-164.

23. C. Kim, B. T. N. Ngoc, K. S. Yang, M. Kojima, Y. A. Kim, Y. J. Kim, M. Endo and S. C. Yang, "Self-sustained thin webs consisting of porous carbon nanofibers for supercapacitors via the electrospinning of polyacrylonitrile solutions containing zinc chloride," Adv. Mater., vol. 19, 2007, pp 2341-2346.

\section{AUTHORS PROFILE}

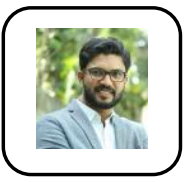

A. Shameem is a Research scholar in the Department of Physics, School of Advanced Sciences at Kalasalingam Academy of Research and Education, India. He received his B.Sc. degree in Physics from Jamal Mohamed College, Tiruchirappalli, in 2010, and his M.Sc. degree in Physics from Government Arts College (Autonomous), Coimbatore, in 2012. His research interest is in the field of nanomaterials for energy and environmental applications.

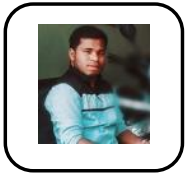

Dr. V. Siva obtained Ph.D. in Physics from Kalasalingam Academy of Research and Education in 2018. He has received his Bachelor's Degree and Master's Degree in Physics from Government Arts College (Autonomous), Coimbatore, which is affiliated to Bharathiar University in the years 2010 and 2012, respectively. He has expertise in the areas of Crystallography, Crystal growth and Computational Physics. To his credit, he has published more than 20 articles in journals of international repute besides ten more as proceedings. Further, he has presented papers in various conferences and seminars. His current research interestisthe development of Metal-Organic Frameworks (MOFs) for sensor and energy storage applications.

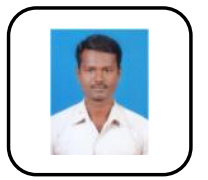

A. Murugan is a Senior Research Fellow in the Department of Physics at Kalasalingam Academy of Research and Education. He has joined as Junior Research Fellow in the Department of Physics under DST-SERB funded project, Govt. of India in the year of 2017. He has received his Master's Degree in Physics from Government Arts College (Autonomous), Coimbatore, which is affiliated to Bharathiar University in the year 2013.His research focus is thin film for solar cell applicationsand the design of materials enhanced for energy applications.

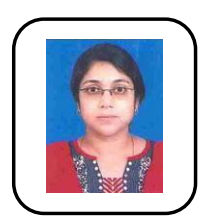

Dr. Shamima Hussain is a Scientist in UGC-DAE Consortium for Scientific Research, Kalpakkam Node Kokilamedu-603104, Tamil Nadu, India since 2011. She had worked as a Postdoctoral Fellow, Semiconductor and Material Spectroscopy Lab, KAUST, Saudi Arabia, 2009 - 2010. Her research interest is on synthesis and characterization of materials especially thin films of II-VI III-V semiconductors, composite materials, materials for photovoltaics, and functional materials.

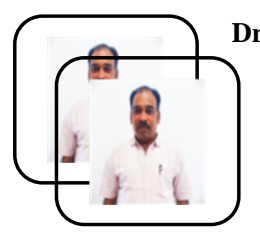

Dr. S. Asath Bahadur is a Senior Professor in the Department of Physics, School of Advanced Sciences at Kalasalingam Academy of Research and Education, India. He has obtained Ph.D. in the area of X-ray crystallography from Madurai Kamaraj University in 1994 and also received his M.Phil. and M.Sc. Degree in physics from Madura Kamaraj University. He has expertise in the areas of Crystallography and Material science. He has published more than eighty-five peer-review research articles in journals of international repute besides seventy more as proceedings. 